\title{
Application of Haddon's matrix in qualitative research methodology: an experience in burns epidemiology
}

This article was published in the following Dove Press journal:

International Journal of General Medicine

23 July 2012

Number of times this article has been viewed

\author{
Reza Deljavan' \\ Homayoun Sadeghi- \\ Bazargani ${ }^{2,3}$ \\ Nasrin Fouladi ${ }^{4}$ \\ Shahnam Arshi ${ }^{5}$ \\ Reza Mohammadi ${ }^{6}$ \\ 'Injury Epidemiology and Prevention \\ Research Center, ${ }^{2}$ Neuroscience \\ Research Center, Department of \\ Statistics and Epidemiology, Tabriz \\ University of Medical Sciences, Tabriz, \\ Iran; ${ }^{3}$ Public Health Department, \\ Karolinska Institute, Stockholm, \\ Sweden; ${ }^{4}$ Ardabil University of \\ Medical Sciences, Ardabil, Iran; \\ ${ }^{5}$ Shahid Beheshti University of Medical \\ Sciences, Tehran, Iran; ${ }^{~ P u b l i c ~ H e a l t h ~}$ \\ Department, Karolinska Institute, \\ Stockholm, Sweden
}

Correspondence: Homayoun SadeghiBazargani

Department of Public Health Sciences,

WHO Collaborating Center on Safe

Communities, Karolinska Institute,

2nd floor, Norrbacka, SE-I7I 76,

Stockholm, Sweden

Email homayoun.sadeghi@gmail.com
Background: Little has been done to investigate the application of injury specific qualitative research methods in the field of burn injuries. The aim of this study was to use an analytical tool (Haddon's matrix) through qualitative research methods to better understand people's perceptions about burn injuries.

Methods: This study applied Haddon's matrix as a framework and an analytical tool for a qualitative research methodology in burn research. Both child and adult burn injury victims were enrolled into a qualitative study conducted using focus group discussion. Haddon's matrix was used to develop an interview guide and also through the analysis phase.

Results: The main analysis clusters were pre-event level/human (including risky behaviors, belief and cultural factors, and knowledge and education), pre-event level/object, pre-event phase/environment and event and post-event phase (including fire control, emergency scald and burn wound management, traditional remedies, medical consultation, and severity indicators). This research gave rise to results that are possibly useful both for future injury research and for designing burn injury prevention plans.

Conclusion: Haddon's matrix is applicable in a qualitative research methodology both at data collection and data analysis phases. The study using Haddon's matrix through a qualitative research methodology yielded substantially rich information regarding burn injuries that may possibly be useful for prevention or future quantitative research.

Keywords: Haddon's matrix, qualitative research methodology, injuries, burns, focus groups, content analysis

\section{Introduction}

Injury epidemiology can be defined as "the study of the distribution and determinants of injuries and safety related states/events in specified populations, and the application of this study to prevent injuries and promote safety." Burns are a major public health issue throughout the world leading to considerable morbidity and mortality, especially in low- and middle-income countries. ${ }^{2}$ Over $90 \%$ of fatal fire related burns occur in developing or low- and middle-income countries. ${ }^{3}$ Burn injuries are an important public health issue in the East Mediterranean region including Iran leading to substantial morbidity and mortality especially among the children. ${ }^{4-7}$ Similar to other injuries, the prevention of burns or decreasing their aftermaths requires adequate knowledge of the epidemiological characteristics as well as current knowledge and perceptions of the victims, and also their reactions and behaviors through the course of an injury event. This knowledge can be achieved when researchers use qualitative methods jointly with quantitative studies to accumulate and interpret possibly useful information 
regarding injuries. Qualitative methodology has recently gained more attention by injury researchers. ${ }^{8-10}$ However, the knowledge in this field, especially the methodological aspects of it, is limited in the literature. Haddon's matrix, which is an extension of the well-known epidemiologic triangle, has been used for decades in injury prevention mainly as a tool to analyze individual injury events and to suggest prevention interventions. Haddon himself first applied it analyzing traffic injuries. ${ }^{11-13}$ While Haddon's matrix is mainly a qualitative tool, using it through well-practiced qualitative research methods such as phenomenology of grounded theory is not well defined in the injury literature. The aim of this study was to investigate the applicability of Haddon's matrix through qualitative research methods to better understand people's perceptions about burn injuries.

A valor is a type of kerosene heater that is is not connected to a chimney. It is used in some areas, especially the rural areas, for a dual purpose of cooking and heating the air. A samovar is a heated metal container traditionally used to heat and boil water for making tea, mostly in Iran, Turkey, and Russia. See our previous articles for pictures of these appliances. ${ }^{14,15}$

\section{Methods}

\section{Haddon's matrix}

Haddon's matrix was first presented to the world of injury epidemiology in 1970 by William Haddon who worked on road safety in the USA. The most common form of Haddon's matrix is a framework table that has four columns and three rows (Table 1). Each row frames the timing of injuries respectively as pre-event phase, event phase, and post-event phase. While designing interventions, factors determining the injury occurrence or predisposing to it, in cases of injury analysis as well as injury prevention, can be depicted at the pre-event phase. For example, improving the brake system in vehicles or legislating speed limits falls in this category. Analyzing the event phase will be valuable when interested in secondary prevention measures. For example, including airbags in the production of vehicles or law enforcement on use of safety belts could be discussed at this phase. Providing adequate health care, however, can be discussed in the postevent phase of Haddon's matrix. The four columns separating each row that are variably named in different studies mainly based on the injury mechanism are as follows:

1. Human (also named as host) column

2. Agent (also named as vector, vehicle, object, equipment, appliance, etc) column

3. Physical environment column

4. Social (economic) environment column.

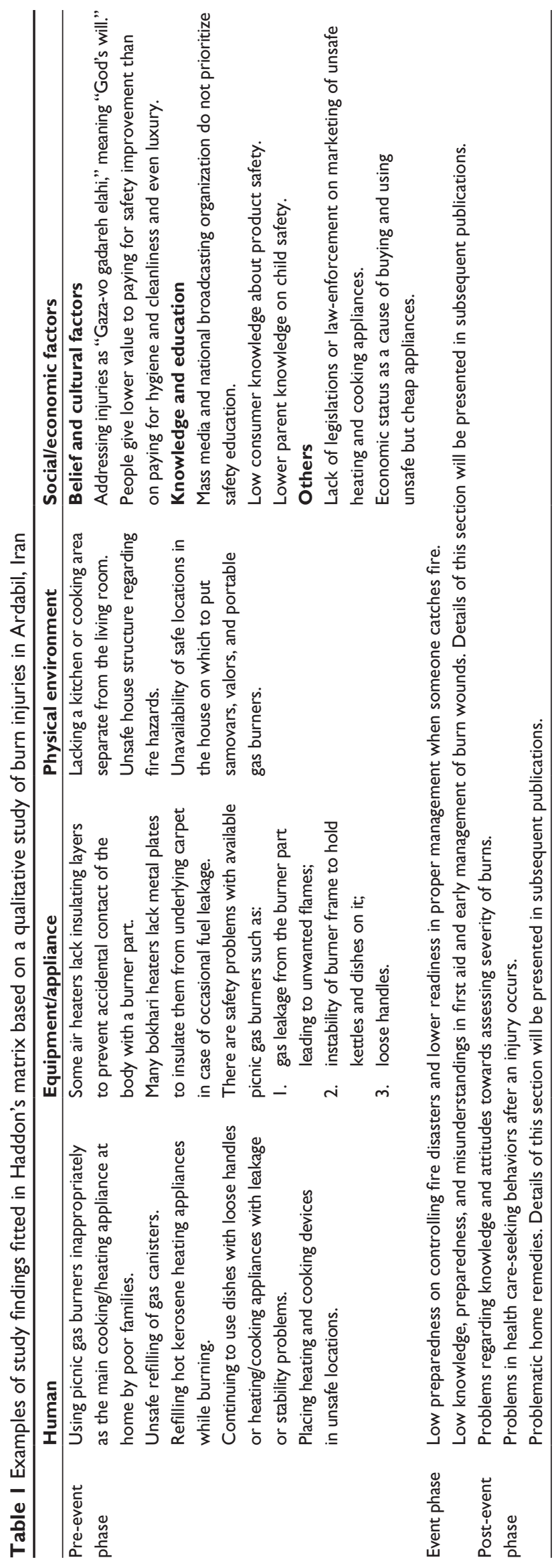


The variety in naming the column headings is inevitable. For example, in cases of wild animal bites, "vector" may be a better alternative to "vehicle," which is appropriate for traffic accidents, or "appliance," which may be preferred in case of domestic burn injuries. Further details about Haddon's matrix may be found in the literature. ${ }^{16-19}$

\section{Design}

A qualitative study was conducted during the years 2007 2008. According to the aim of this study, focus group discussion was selected as the method to collect and generate data. This approach generates data from the synergy of the group interaction and environment, particularly when people with similar backgrounds are brought together and discuss issues that affect their lives. Focus groups are a way of collecting qualitative data from multiple individuals simultaneously that are appropriate but not limited to use in the study of communication gaps or barriers between groups of people. ${ }^{20}$

\section{Participants}

The study was conducted in Ardabil province located in the north-west of Iran. Ardabil province is a mountainous area with a population of $1,200,000$ people. The native language of the inhabitants is Azeri Turkish. Nomads comprise nearly $7 \%$ of this population and many people living in some areas of Ardabil province are the settled generation of earlier nomadic parents. Participants were mainly recently burned patients from an injury surveillance system as well as patients hospitalized due to burn injuries at a provincial burn center. A purposeful sampling method was used for two strata existing both in gender (male versus female) and age (child versus adult) groups. Considering the fact that the attitudes, perceptions, and experiences of the people regarding the burn injuries as well as the injury patterns may differ based on injury mechanism and severity, study subjects were purposefully sampled to include these variations and to ensure acquisition of rich information related to the aim of qualitative study. This was also promising with respect to the specific methodological objective focused on in the present study. Travelling costs were provided to motivate those living in rural areas to also participate in the study. Nevertheless, one of victims did not manage to participate due to personal reasons. Most of the hospitalized burn victims were those discharged through the recent month before enrollment in the study and outpatient victims were also enrolled not later than the date they had been burned. All the participants were Azeri Turkish speaking inhabitants of Ardabil province. The patients were invited by telephone to participate in focus group discussion sessions. They were informed of the study purpose and received a reminder telephone call from the research assistant one day before the meeting. In total, six focus groups were conducted by one of the researchers, enrolling 48 burn victims. The victims had been burned through different injury mechanisms such as flame burns, scalds, contact burns, and electrical burns. A variation of burn extent existed among victims with a 5\%-60\% range of total body surface area burned. One of the victims had survived after $60 \%$ of their total body surface area was burned.

Two sessions of group discussions were organized for male adults and two sessions for female adults. Gender separation in some focus groups is suggested to prevent tensions and comfortable circulation of ideas. ${ }^{21}$ Therefore, to facilitate idea circulation and also consider cultural limitations, discussion groups were held separately for men, women, and children. Each adult focus group consisted of 7-9 burned persons occasionally accompanied by close relatives. This was observed in one case in which the mother accompanied her young daughter but did not noticeably contribute to the ongoing discussions. Two sessions of group discussion were also organized for child burn victims accompanied by their parents. Both parents and the children contributed to discussions. The oldest child participant was 14 years old and the youngest adult participant was 16 years old. The age range of the burn victims in the child groups was 2-14 years. The age range was $20-52$ years in the adult male groups and $16-50$ years in the adult female groups. Child group discussions were a bit larger due to accompanying parents. Less than a quarter of adult participants were civil servants and others were self-employed or unemployed. An additional focus group was also conducted with experts from the fire brigade, an expert from a national gas organization, a social medicine specialist, an epidemiologist with injury research experience, and a public health expert. The aim of including this focus group was to discuss the primary findings from the aforementioned six groups of burn victims to increase the validity of the analysis.

\section{Data collection procedure}

An interview guide was developed with open questions. The moderator and the participants were all of the same ethnicity and spoken language. Each of the focus groups met in a private room facilitated by the main investigator. He had good experience regarding the burns and injury research.

Participants were informed that discussion would be tapeor video-recorded and that notes would be taken. They were assured of the confidentiality of the recordings and notes. In 
those sessions in which video recording was used, a stationary camera was placed in a corner to provide the best angle. Video recording was not used in female discussion groups. Haddon's matrix in this research was used once at the data collection phase to prepare follow-up questions, to raise complementary questions in areas that adequate information had not emerged regarding some of the matrix cells, and finally helped data saturation. Data saturation describes the situation in which the data is repeatedly encountered and no new beneficial information emerges. Data saturation is assumed to happen sooner depending on the skill of the researchers or the power of the methodology in acquiring richer information from the participants. The researcher started after ice-breaking, with an opening question such as, "Could you tell us how you got burned?" Usually a later follow-up question was posed in all groups, such as, "What do you or other people do when burns happen?" In child groups children introduced themselves and were also given the opportunity to participate in discussions independently. The discussions of each group lasted approximately 1.5-2 hours until no new information was emerging. The researchers finalized the group discussions after six focus group sessions because no new or significant data were emerging at that point.

\section{Data analysis}

To minimize omission of data, the researcher and research assistant debriefed each other immediately after each meeting. Data were completely transcribed from each audiotape or videotape by the research assistant, and the transcription was used for the analysis of content and categorization of common themes. In total 120 pages were transcribed for the analyses.

Analysis of content was done by the following steps:

1. Selecting statements as units of analysis.

2. Coding meaningful statements, with the researchers reading the transcriptions line by line.

3. Formulating themes from meaningful statements.

4. Summarizing the themes into a priori categories of Haddon's matrix ("clustering").

5. Assessing reliability by systematically checking the accuracy of coding by each researcher until full agreement is reached.

6. Assessing validity, in the case of disagreement, through confirmation by returning to the original text to find examples of categories and resolution through discussion.

7. Reassessing validity and finalizing the results after group discussion of experts.
Through the analysis, Haddon's matrix was applied to organize a structure of results mainly at the clustering phase. Coding and developing themes started from the data level at the bottom, clustering towards an upper a priori structure of Haddon's matrix. For example, information from statements of a participant about running and asking for help when on fire and the discussions posed regarding this situation was directed in a category to be placed in the event/human cross-tabulation cell in Haddon's matrix. Researchers did not stick with the original format of the Haddon's matrix to keep all matrix cells in the final categorizing. So we considered subdividing cells into categories as they emerged and in cases of paucity or overlaps, merged some of the matrix cells.

The ethics committee of Ardabil University of Medical Sciences approved the study.

\section{Results}

\section{Pre-event level: human and social environment}

\section{Risky behaviors}

The information that emerged was indicative of possible risky behaviors capable of causing burns. The following risky behaviors were discussed: the refilling of gas canisters by non-expert service providers or even family members, especially in rural areas: refilling kerosene heating/cooking appliances like valors and samovars without extinguishing them prior to fueling; fixing impaired gas burners by family members; continuing to use heating and cooking appliances that have loose handles, leakage, and/or stability problems; not doing timely safety checks of heating and cooking appliances and not replacing gas tubes until a problem is detected; refilling gas canisters inside a building; unsafe storage of fuels; using traditional heaters for a dual purpose of cooking and heating the air; burning garbage in rural areas as a way to get rid of it; placing heating and cooking appliances in unsafe locations; hot material being carried by physically incapable people; carrying hot material or hot dishes without using potholders; not taking precautions in limiting child access to risky materials such as hot liquids, lighters, matches, heating/cooking appliances, and fuel storage; freely walking or running children in cooking areas where they may bump into hot liquid containers and hot objects or kerosene-burning appliances; leaving children unsupervised in unsafe conditions; boiling water left in proximity of children - a hazard inherent in the traditional method of cooking rice for ceremonies; and, lastly, the popular use of cheap and easily portable gas burners like picnic gas burners. 


\section{Beliefs and cultural factors}

Many people think that accidents are just incidents that should have happened. Some called it "Gaza-vo gadareh elahi," meaning "God's will": "I don't say that we must not be cautious but we can't deny God's will; if it is the God's will then it will happen."

People think that the main danger when traditional heaters like valors are used to heat the air will be smoke suffocation. They had stories to narrate about people who suffocated in old times. Nearly all of the participants said that kettles of boiling water should be put on valors to prevent smoke suffocation because steam is the choice neutralizer of smoke. People give lower value to paying for safety improvement than to pay for hygiene and cleanliness and even to pay for luxury. Some people think samovars should be put on the tablecloth within hands reach while eating breakfast. Safety did not seem to be the main criteria in buying a heating/cooking appliance.

\section{Knowledge and education}

Low consumer knowledge about product safety and unsafe behaviors was apparent. Some of the participants said they teach safety to their children but when asked, "What do you teach them?" they had nothing to say except for statements such as "be careful" and "don't touch matches."

Safety-targeted or safety-related TV or radio programs regarding burn injuries are quite scarce. The available programs are limited to those financially supported by the National Gas Organization (focused on gas explosions, leakages, and suffocation) and electricity hazards provided by the Ministry of Power and Energy. No one could remember a TV or radio program on scald prevention or cooking safety other than the above.

\section{Pre-event level: object/appliance}

The main problem with product safety of the picnic gas burners was stated to be gas leakage from the burnercanister connection leading to ectopic flames coming out of the connection area. Another problem was stated to be instability of the burner frame to hold kettles and dishes. Finally, loose handles were the last product safety problems discussed in the focus groups. Occasionally overpressurized refilling of canisters leads to unsafe ectopic flames. This persuades users to empty the extra gas sometimes inside the kitchen. Many traditional kerosene heaters manufactured in Iran are not controlled by a national standards organization. There is no definite legislation or at least supervision on shopkeepers not to sell nonstandard heating/cooking appliances.
Some air heaters lack insulating shields to prevent accidental contact of the body with a burner part. Many participants preferred to buy such cheap brands and did not even consider them to be unsafe.

One of the problems with Bokharies (traditional Iranian kerosene air heaters) narrated by the participants was that sometimes they get extinguished while fuel continues to run into the burning chamber. This may cause the kerosene to leak from the bottom of the Bokhari onto nearby clothing or underlying carpets. Later if the Bokhari is turned on again on top of the leakage it may cause a fire catastrophe. Some people use metal plates under Bokharies and some Bokharies have such a plate included in factory production.

\section{Pre-event phase: environment}

Hazards discussed by the focus groups included: lacking a kitchen or cooking area separate from the living room; unsafe house structure regarding fire hazards; unavailability of safe locations in the house for putting samovars, valors, and portable gas burners; in some old-fashioned rural houses the kitchen is located in a yard corner separate from the main building.

\section{Event and post-event phase}

The information that emerged from this group was very rich and details are going to be published separately. As such, just the main headings in this group are presented here.

1. Fire control

2. Emergency scald and burn wound management

3. Medical consultation

4. Severity indicators.

As an example, it was discussed that traditional or homemade remedies were highly popular among victims and were used before taking medical consultation, along with prescribed medicine, and after release from the hospital. Table 1 presents examples of the results fitted in Haddon's matrix.

Generally, the perceptions were highly similar among groups. However the bulk of the information taken from the child groups differed substantially in the pre-event level.

\section{Discussion}

In regards to the aim of the study focused on in this paper, we are going to discuss only the methodological aspects of using Haddon's matrix in this article. Haddon's matrix, developed by William Haddon, ${ }^{11-13}$ has been used for decades in injury prevention research and interventions. Some people might think of Haddon's matrix as a tool for analyzing single 
injuries. However, by dissecting a problem into its dimensions of time and contributing factors, Haddon's matrix can be considered as an epidemiological tool and it can also be applied as a practical user-friendly interdisciplinary brainstorming and planning tool to help understand, prepare for, and respond to, a broad range of public health emergencies. $^{22}$

Haddon's matrix has been used both to conceptualize etiologic factors for injury and to identify potential preventive strategies. ${ }^{18,19}$

The authors found Haddon's matrix to be helpful when used through classic qualitative research methodology. Some advantages of this were as follows:

1. Using Haddon's matrix helped to design better objectives and key questions for data collection. As injury prevention programs are stated to benefit from information derived using Haddon's matrix, the results of the present study applying Haddon's matrix are assumed to be more useful for prevention purposes.

2. Using Haddon's matrix helped the facilitator to reveal overlooked areas through the group discussions and to stimulate circulation of ideas leading to improved data saturation. However, using it is not a guarantee for the ideal richness of collected information, as in this research we found that no information was retrieved regarding the role of clothing in burn injuries.

3. Analysis made on this method may improve the findings and discussion to be more useful for injury prevention.

Using a priori categories or classes for clustering as done in our research is an acceptable practice in qualitative research methodology. Clustering is a tactic that can be applied at many levels of qualitative data. In all instances, we're trying to understand the phenomenon better by grouping and conceptualizing objects that have similar patterns or characteristics. ${ }^{23}$ The interaction between upward and downward direction of information flow, using Haddon's matrix in this research, formed the structure of the final results. Blumer points out, as referred by Miles and Huberman, that clusters emerge from an interaction of theory and data, ${ }^{23}$ and we may not just expect an upward flow in structuring the results.

Although using Haddon's matrix in clustering can increase the clarity of results and decrease cluster overlapping, it must also be taken into account that different users of the Haddon's matrix would identify different host factors or have different depictions of the same host factor according to the theoretical conceptual framework they use. ${ }^{16}$ With reference to the "Results" section, merging and splitting some cells of Haddon's matrix, contrary to what researchers expected, was inevitable due to the paucity of information in some cells and the abundance of information in other cells of Haddon's matrix. As discussed above, results come from the interaction of theory and data, so using Haddon's matrix in this way doesn't mean that results should be categorized in the same cells as in the original matrix.

The present study revealed substantially rich information regarding burn injuries that may be useful for prevention or future research, especially at the event and post-event phases. Using Haddon's matrix through a qualitative research methodology can yield beneficial results in burn injury research and possibly in other fields of injury research and prevention. The knowledge garnered by the use of Haddon's matrix may be helpful in the development of preventive strategies and methods including efficient and reliable qualitative research results. This is because abundant information is generated regarding burn injuries and the perceptions of people about the problem separated into pre-event, event, and post-event phases.

Regardless of the beneficial role of Haddon's matrix in this study, which the authors believe improves data saturation and leads to richer information emerging when compared with data collection methods in qualitative research by creating the categories through an upwards direction of information stream, we would like to note that using this methodology does not guarantee that the study will retrieve every piece of information and it does not underscore the necessity of having an expert injury researcher in the team.

\section{Conclusion}

Haddon's matrix is applicable in qualitative research methodology both at data collection and data analysis phases. The study using Haddon's matrix through a qualitative research methodology yielded substantially rich information regarding burn injuries that will possibly be useful for prevention or future quantitative research.

\section{Acknowledgments}

The authors thank professor Per Tillgren for reading the whole manuscript and improving it. The authors thank managers, physicians, and staff in the Ardabil health network and hospitals who helped in conducting this research. They also thank SIDA from Sweden and the Iranian Ministry of Health for supporting the research.

\section{Disclosure}

The authors report no conflicts of interest in this work. 


\section{References}

1. Sadeghi-Bazargani H. Injury epidemiology and publishing injury research. J Inj Violence Res. 2012;4(1):1.

2. Heimbach D. Burn patients, then and now. Burns. 1999;25(1):1-2.

3. Forjuoh SN. Burns in low- and middle-income countries: a review of available literature on descriptive epidemiology, risk factors, treatment, and prevention. Burns. 2006;32(5):529-537.

4. Othman N, Kendrick D. Epidemiology of burn injuries in the East Mediterranean Region: a systematic review. BMC Public Health. 2010; 10:83.

5. Sadeghi-Bazargani H, Mohammadi R. Epidemiology of burns in Iran during the last decade (2000-2010): review of literature and methodological considerations. Burns. 2012;38(3):319-329.

6. Arshi S, Sadeghi-Bazargani H, Mohammadi R, et al. Prevention oriented epidemiologic study of accidental burns in rural areas of Ardabil, Iran. Burns. 2006;32(3):366-371.

7. Arshi S, Sadeghi-Bazargani H, Mohammadi R, Soltan Mohammad Zadeh M, Rouhi A, Barak M. Burns comprising 3/4th of home injuries in pre-school children of the rural areas of Ardabil Province, Iran. J Med Sci. 2007;7(2):248-251.

8. Lambert JH, Peterson KD, Joshi NN. Synthesis of quantitative and qualitative evidence for accident analysis in risk-based highway planning. Accid Anal Prev. 2006;38(5):925-935.

9. Ramos P, Díez E, Pérez K, Rodriguez-Martos A, Brugal MT, Villalbí JR. Young people's perceptions of traffic injury risks, prevention and enforcement measures: a qualitative study. Accid Anal Prev. 2008; 40(4):1313-1319.

10. Wong SC, Leung BS, Loo BP, Hung WT, Lo HK. A qualitative assessment methodology for road safety policy strategies. Accid Anal Prev. 2004;36(2):281-293.

11. Anderson R. Injury causation, injury prevention and safety promotion. In: Laflamme L, Svanstrom L, Schelp L, editors. Safety Promotion Research. 1st ed. Stockholm: Kristianstads boktryckeri AB; 1999: $15-42$.

12. Haddon W Jr. Energy damage and the ten countermeasure strategies. Hum Factors. 1973;15(4):355-366.
13. Haddon W Jr. Editorial: Strategy in preventive medicine: passive vs active approaches to reducing human wastage. J Trauma. 1974;14(4): 353-354.

14. Sadeghi-Bazargani H, Mohammadi R, Arshi S, Svanstrom L, Ekman R. The risks of using samovars as the main tea-preparing facility in some Eastern countries. Burns. 2008;34(8):1149-1152.

15. Sadeghi-Bazargani H, Arshi S, Mashoufi M, Deljavan-Anvari R, Meshkini M, Mohammadi R. Household related predictors of burn injuries in an Iranian population: a case-control study. BMC Public Health. 2012;12(1):340.

16. Lu TH. Unalterable host factors? A social epidemiologist's view of the Haddon matrix. Inj Prev. 2006;12(5):285-286.

17. Peck MD, Kruger GE, van der Merwe AE, et al. Burns and injuries from non-electric-appliance fires in low- and middle-income countries Part II. A strategy for intervention using the Haddon Matrix. Burns. 2008;34(3):312-319.

18. Runyan CW. Using the Haddon matrix: introducing the third dimension. Inj Prev. 1998;4(4):302-307.

19. Runyan CW. Introduction: back to the future - revisiting Haddon's conceptualization of injury epidemiology and prevention. Epidemiol Rev. 2003;25:60-64.

20. Dahlgren L, Emmelin M, Winkwist A. Qualitative Methodology for International Public Health. Umea: Umea University; 2004.

21. Johnson I, Tillgren P, Hagströmer M. Understanding and interpreting the concept of physical activity - a focus group study among Swedish women. Scand J Public Health. 2009;37(1):20-27.

22. Barnett DJ, Balicer RD, Blodgett D, Fews AL, Parker CL, Links JM. The application of the Haddon matrix to public health readiness and response planning. Environ Health Perspect. 2005;113(5): 561-566.

23. Miles MB, Huberman AM. Qualitative Data Analysis: An Expanded Sourcebook. 2nd ed. Thousand Oaks: Sage Publications; 1994.
International Journal of General Medicine

\section{Publish your work in this journal}

The International Journal of General Medicine is an international, peer-reviewed open-access journal that focuses on general and internal medicine, pathogenesis, epidemiology, diagnosis, monitoring and treatment protocols. The journal is characterized by the rapid reporting of reviews, original research and clinical studies across all disease areas.

\section{Dovepress}

A key focus is the elucidation of disease processes and management protocols resulting in improved outcomes for the patient. The manuscript management system is completely online and includes a very quick and fair peer-review system. Visit http://www.dovepress.com/ testimonials.php to read real quotes from published authors. 